\title{
EVALUASI PRODUK SEPATU WANITA BAGI UKM KLASTIK FOOTWEAR MENGGUNAKAN METODE CHOICE BASED CONJOINT
}

\author{
Rizqa Amelia Zunaidi ${ }^{1 *}$, Sinta Dewi ${ }^{2}$ \\ ${ }^{1,2}$ Program Studi Teknik Industri, Institut Teknologi Telkom Surabaya, \\ Jl. Gayungan PTT No.17-19 Surabaya 60234 \\ *e-mail : rizqazunaidi@ittelkom-sby.ac.id
}

\begin{abstract}
In Indonesia, there are three industrial sectors with the largest number of Small Medium Enterprises (SMEs) from 2010 to 2014: food, clothing, and wood. Klastik Footwear is one of the SMEs in Indonesia that focuses on the footwear industry, especially women's shoes. Klastik Footwear brings classic and ethnic themes to its products. In order to be well received by the market, Klastik Footwear wants to identify potential consumer groups formed from market segmentation and assess the preferences of each group on Klastik Footwear products. In this study, the choice based conjoint analysis method is used to determine potential consumer preferences for Klastik Footwear products. From the results of the conjoint analysis, the importance and part-worth level of each attribute will be known. Next, a cluster and market simulator analysis is performed to see the profile of the formed segments. The results showed that there are 3 groups of potential consumers. After conducting market simulation on the three groups, it is predicted that the most ordered Klastik Footwear products by consumers are Galuh, Ara, Srikandi, and Gendhis 2 (in group 1); Brastagi, Telaga, and Gendhis 2 (in group 2); and Rinjani, Galuh, and Soko (in group 3).
\end{abstract}

Keywords: Claster Analysis, Choice Based Conjoint Analysis, Market Simulator, SME, Shoes

\section{Pendahuluan}

Jumlah wirausahawan di Indonesia, yang mencakup pengusaha industri besar, industri sedang, maupun industri kecil dan menengah, hingga Agustus 2014 mencapai 43.938 .845 orang atau $17,2 \%$ dari total jumlah penduduk Indonesia dengan jumlah pengusaha tersebut terdiri dari jumlah wirausahawan yang berusaha sendiri 20,48 juta orang, berusaha dibantu buruh tidak tetap 19,27 juta orang dan berusaha dibantu buruh tetap 4,17 juta orang. Jumlah wirausahawan tersebut meningkat dari tahun 2013 yang sebesar 42,4 juta orang (Badan Pusat Statistik, 2014). Jumlah wirausahawan di Indonesia mulai dari skala kecil atau UKM diperkirakan akan terus meningkat dalam lima hingga sepuluh tahun yang akan datang jika Indonesia dapat meningkatkan ease of doing business hingga peringkat 50 besar dunia. Menurut International Finance Corporation, saat ini Indonesia berada pada urutan 73 atau naik 55 peringkat dibanding tahun 2013. Pengusaha tersebut tersebut bergerak di sektor yang berbedabeda, mulai dari sektor industri pangan hingga sektor industri jasa. Sektor industri pangan, industri sandang dan industri kayu merupakan tiga sektor yang memiliki jumlah UKM terbanyak dari tahun 2010 hingga 2014. Jumlah usaha di ketiga sektor industri itupun terus meningkat. Namun sempat terjadi penurunan jumlah pada industri sandang di tahun 2013. Walaupun produk-produk sandang sempat mengalami penurunan jumlah di tahun 2013, namun pada tahun 2014 jumlahnya meningkat kembali. Industri sandang memiliki 
beberapa jenis produk, seperti produk tekstil, produk pakaian jadi, dan produk alas kaki (Badan Pusat Statistik, 2014).

Produk alas kaki sendiri mengalami perkembangan yang cukup baik. Dahulu produk alas kaki masih didominasi oleh produsenprodusen luar negeri. Namun, saat ini, sudah banyak produsen alas kaki lokal yang memiliki kualitas produk yang sangat baik dan mampu diekspor ke luar negeri. Berdasarkan data pemerintah Indonesia, pangsa pasar alas kaki buatan Indonesia di pasar internasional mencapai 2,85\% pada tahun 2016 dan berhasil mencapai 6 besar setelah Cina, Italia, Vietnam, Jerman, dan Belgia (Muliatie \& Riyadi, 2019).

UKM sendiri telah menjadi penyelamat ekonomi Indonesia saat terjadi kriris ekonomi di tahun 1998. Pada saat itu, hanya UKM yang mampu berdiri kokoh saat banyak usaha skala besar yang mengalami kebangkrutan (Suci, 2017). Dibalik kontribusi UKM yang cukup besar pada ekonomi nasional, UKM juga memiliki permasalahan dasar yang perlu diselesaikan, seperti manajemen usaha, termasuk manajemen SDM, keuangan dan pemodalan, serta pemasaran produk (Sudaryo \& Purnamasari, 2017). Banyak pelajaran yang dapat diambil oleh UKM yang bergerak di industri sandang dari perusahaan besar. Pertama, UKM harus memikirkan konsep produk, target pasar, harga, promosi serta lokasi dengan baik agar UKM dapat memposisikan produknya di pasar dengan tepat. Konsep produk yang akan dipasarkan harus jelas dengan brand yang dapat menggambarkan dengan baik konsep produk tersebut. UKM juga harus menentukan target pasar yang sesuai dengan konsep produk yang akan dibawa serta menentukan harga yang sesuai untuk target pasar tersebut. Kedua, UKM harus mengutamakan kualitas produk karena konsumen Indonesia mengutamakan kualitas produk dalam memilih produk yang akan dibeli. Ketiga, UKM sebaiknya bekerja sama dengan sosok-sosok yang terkenal di kalangan masyarakat Indonesia untuk mendapatkan perhatian dari target pasar. Keempat, UKM harus memelajari bagaimana perilaku konsumen dalam membeli produk. Kelima, UKM harus dapat menciptakan manajemen yang baik terutama terkait dengan inventori. UKM harus dapat meramalkan pasar serta penjualan produknya (Sugih \& Soekarno, 2014). Hal tersebut juga sejalan dengan publikasi Pemerintah Kota Bandung yang menyatakan bahwa masalah umum UKM di Kota Bandung adalah pemasaran, persaingan bisnis, akses modal, infrastruktur, biaya bahan baku yang tinggi, cuaca, akses bahan baku, dan teknologi (Sidharta \& Lusyana, 2014; Machmud \& Sidharta, 2016).

Klastik Footwear merupakan salah satu UKM yang bergerak di bidang industri alas kaki di Indonesia, khususnya industri sepatu wanita dan telah memroduksi berbagai macam model sepatu wanita, mulai dari sepatu sandal, flatshoes, heels, hingga wedges. Berbagai seri produk juga sudah diproduksi oleh Klastik Footwear untuk semua wanita usia 18 hingga 34 tahun. Klastik Footwear memiliki strategi bisnis diferensiasi produk karena mengangkat motif kain tradisional Indonesia. Produk-produk yang ditawarkan Klastik Footwear saat ini berbeda dengan produk-produk yang sudah ada di pasar. Strategi diferensiasi produk yang dibawa Klastik Footwear mengharuskannya untuk terus berinovasi untuk mengembangkan produknya dan menciptakan produk-produk baru agar produk yang dihasilkan berbeda dengan produk-produk sepatu wanita yang saat ini di pasar.

Saat ini, Klastik Footwear memiliki banyak variansi produk yang bertujuan untuk memberikan lebih banyak alternatif yang dapat dipilih oleh konsumen potensialnya, tetapi banyaknya variansi produk tidak terlalu mempengaruhi pilihan konsumen. Konsumen cenderung memilih produkproduk tertentu saja, sehingga ada beberapa produk yang dirasa oleh Klastik Footwear kurang diminati oleh konsumen. Oleh sebab itu, pemilik Klastik Footwear ingin mengurangi beberapa variansi produknya dan hanya mempertahankan produk-produk yang diprediksi akan sering dipesan oleh konsumen potensialnya.

Klastik Footwear perlu melakukan riset pasar mengenai preferensi konsumen tersebut terhadap produk mereka untuk mengetahui produk mana yang diprediksi akan sering dipesan konsumen potensial serta untuk mengembangkan produknya agar sesuai dengan selera pasar. Setiap konsumen tentu memiliki preferensi yang berbeda-beda mengenai produk Klastik Footwear. Namun jika 
Klastik Footwear ingin mengidentifikasi bagaimana preferensi masing-masing konsumen secara individu akan membutuhkan lebih banyak waktu. Oleh sebab itu, Klastik Footwear perlu mengelompokkan konsumen potensial dalam beberapa kelompok dan mengidentifikasi preferensi masing-masing kelompok konsumen potensial yang terbentuk terhadap produk mereka.

\section{Landasan Teori}

Banyak tools yang dapat digunakan untuk meneliti preferensi konsumen mengenai suatu produk, seperti structural equation modelling, analisis korelasi kanonis, analisis variansi multivariat, regresi majemuk, analisis konjoin, analisis diskriminan, model probabilitas linier, analisis faktor, analisis klaster, multidimensional scalling, dan analisis koresponden (Maholtra \& Birks, 2007). Pada penelitian ini, digunakan analisis klaster untuk mengidentifikasi kelompok konsumen potensial Klastik Footwear yang terbentuk dari riset pasar serta analisis konjoin untuk menilai bagaimana preferensi masingmasing kelompok konsumen potensial yang terbentuk terhadap produk-produk Klastik Footwear.

Analisis konjoin dipilih dalam penelitian ini karena analisis ini dapat mempelajari reaksi dan evaluasi konsumen terhadap kombinasi atribut yang mewakili produk atau jasa (Kuzmanovic, Martic, \& Gusavac, 2011). Analisis konjoin juga dapat memberikan gambaran mengenai komposisi preferensi konsumen karena derajat realisasinya yang tinggi. Selain itu, analisis konjoin juga dapat digunakan untuk segmentasi pasar berdasarkan preferensi konsumen terhadap atribut tertentu dengan menggunakan analisis klaster (Kosasih, Salomon, \& Hutomo, 2017).

Analisis konjoin adalah teknik statistik multivariat berbasis survey yang secara khusus digunakan untuk mempelajari bagaimana responden membuat preferensi terhadap produk atau jasa (Dauda \& Lee, 2016). Hal ini berdasarkan premis sederhana bahwa konsumen mengevaluasi produk atau jasa dengan cara mengkombinasikan sejumlah nilai terpisah yang dimiliki tiap atribut dari produk atau jasa. Nilai yang ditawarkan oleh masing-masing atribut disebut level. Analisis konjoin akan mengukur tingkat kegunaan (utility) dari berbagai level dan nilai kepentingan relatif dari berbagai atribut suatu produk atau jasa (Hair, Black, Babin, \& Anderson, 2010). Nilai kegunaan level dan nilai kepentingan relatif atribut tersebut dapat digunakan untuk membantu menyeleksi atribut-atribut suatu produk yang akan ditawarkan dan menghasilkan suatu konsep produk baru (Bleibaum, Kern, \& Thomas, 2017).

Analisis konjoin tergolong metode tidak langsung (indirect method). Kesimpulan diambil berdasarkan respons subyek terhadap perubahan sejumlah atribut. Karena itu, perlu dipastikan terlebih dahulu apa saja atribut suatu produk (Simamora, 2005). Pada dasarnya analisis ini menggunakan stimulus-stimulus. Setiap stimulus dapat berupa produk, merek atau barang yang dijual dipasar. Analisis konjoin memiliki 3 jenis metode pengolahan data, yaitu traditional conjoint, choice based conjoint dan hybrid conjoint.

Disisi lain analisis klaster adalah salah satu teknik multivariat yang bertujuan untuk mengelompokkan objek bedasarkan kesamaan karakteristiknya (Hair, Black, Babin, \& Anderson, 2010). Kriteria pengelompokan yang berbeda akan menghasilkan pengelompokan yang berbeda pula, sehingga satu populasi tertentu dapat dikelompokkan dengan berbagai cara sesuai dengan tujuan dan kebutuhannya. Objek yang dikelompokkan dapat berupa produk (barang dan jasa), benda, manusia (konsumen, responden, dan lain-lain) sehingga klaster-klaster yang terbentuk memiliki homogenitas internal yang tinggi dan heterogenitas eksternal yang tinggi. Dari berbagai jenis pengelompokan di atas, tidak ada yang dapat dikatakan paling benar karena masing-masing pengelompokan memiliki arti tersendiri.

Berbeda dengan teknik multivariat lainnya, analisis ini tidak mengestimasi set variabel secara empiris, namun sebaliknya, menggunakan set variabel yang ditentukan oleh penggunanya. Fokus dari analisis klaster adalah membandingkan objek berdasarkan suatu set variabel yang merepresentasikan karakteristik dari anggota klaster tersebut. Hal tersebut menyebabkan para ahli berpendapat bahwa proses mendefinisikan set variabel sebagai tahap kritis dalam analisis klaster. Solusi analisis klaster bersifat tidak unik. Anggota klaster untuk tiap penyelesaian/solusi tergantung 
pada beberapa elemen prosedur dan beberapa solusi yang berbeda dapat diperoleh dengan mengubah satu elemen atau lebih. Solusi analisis ini secara keseluruhan bergantung pada variabelvariabel yang digunakan sebagai dasar untuk menilai kesamaan. Karena itu, penambahan atau pengurangan variabel-variabel yang relevan dapat mempengaruhi hasil analisis klaster. Hasil klaster yang terbentuk dengan baik memiliki homogenitas yang tinggi antar anggota dalam satu klaster (within-klaster) dan heterogenitas yang tinggi antara klaster satu dengan klaster lainnya (between-klaster) (Hair, Black, Babin, \& Anderson, 2010).

\section{Metodologi Penelitian}

Pada penelitian ini data mentah diolah menggunakan metode choice based conjoint. Metode choice based conjoint memiliki beberapa kelebihan dibandingkan dengan metode traditional conjoint. Kelebihan pertama ialah metode choice based conjoint menghasilkan hasil yang lebih presisi dibanding dengan traditional conjoint jika jumlah atribut yang digunakan relatif sedikit. Metode konjoin ini akan menghasilkan hasil yang optimal jika jumlah atribut tidak lebih dari 6 atribut (Simamora, 2005).

Penelitian ini akan melibatkan lima atribut sehingga metode choice based conjoint lebih sesuai untuk digunakan daripada metode traditional conjoint. Kelebihan kedua dari metode choice based conjoint adalah pertanyaanpertanyaan dalam choice based conjoint lebih simpel dan realistis sehingga mudah dimengerti oleh seluruh responden. Pertanyaan-pertanyaan dalam choice based conjoint juga serupa dengan perilaku pasar yang nyata karena pada kenyataanya konsumen sering dihadapkan pada lebih dari satu pilihan sekaligus. Choice based conjoint juga menyediakan pilihan "tidak memilih sama sekali”, serta waktu yang diperlukan untuk mengisi kuesioner choice based conjoint lebih sedikit dari pada traditional conjoint.

Dalam penelitian ini, digunakan metode hierarchical cluster dan K-means cluster. Metode hierarchical cluster digunakan untuk menentukan jumlah klaster dan mengelompokkan responden, sedangkan metode $K$-means cluster digunakan untuk menguji konsistensi hasil pengelompokkan dengan metode hierarchical cluster. Analisis klaster dengan metode hierarchical cluster yang digunakan pada penelitian ini memiliki beberapa kelebihan yaitu metode ini cocok digunakan untuk penentuan kelompok yang sama sekali belum ada dasar teorinya. Dengan menggunakan metode ini, peneliti juga dapat dengan mudah melihat proses penggabungan masing-masing individu menjadi kelompok dengan bantuan dendogram sehingga bila terdapat outlier dari data responden dapat terdeteksi oleh peneliti. Gambar 1 merupakan tahapan penelitian ini.

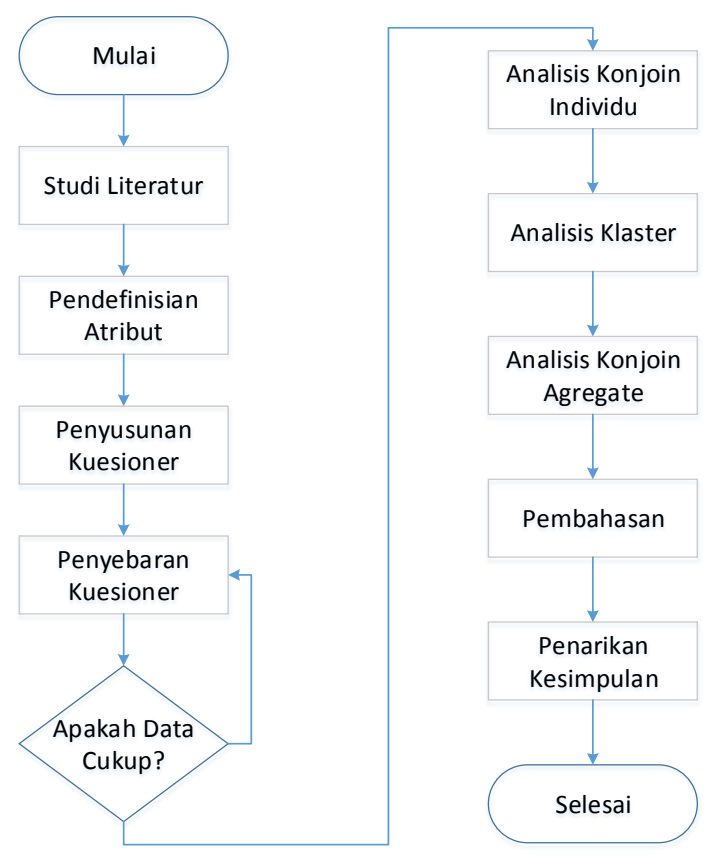

Gambar 1. Diagram Alir Penelitian

\section{Hasil dan Pembahasan \\ 4.1 Pendefinisian Atribut}

Variabel yang digunakan pada penelitian ini mengacu pada konsep produk menurut dimensi kualitas Garvin. Garvin menggunakan delapan dimensi kualitas, yaitu aesthethhic, conformance, performance, feature, perceived quality, reliability, durability, dan serviceability.

Kedelapan dimensi Garvin tersebut akan diturunkan menjadi indikator-indikator yang menjelaskan dimensi tersebut. Selanjutnya indikator tersebut akan diturunkan menjadi atributatribut produk yang akan diidentifikasi oleh Klastik Footwear. Penurunan dimensi Garvin dan penentuan variabel penelitian dilakukan melalui brainstorming dengan pemilik Klastik Footwear. 
Brainstorming tersebut dilakukan agar variabel yang digunakan pada penelitian ini sesuai dengan konsep produk oleh Klastik Footwear. Dari hasil penurunan di atas, atribut dan level yang digunakan pada penelitian ini seperti pada Tabel 1 .

Tabel 1. Atribut dan Level

\begin{tabular}{lll}
\hline \multicolumn{1}{c}{ Atribut } & & Level \\
\hline Motif kain etnik & $\bullet$ & Batik \\
yang digunakan & $\bullet$ & Songket \\
& $\bullet$ & Tenun \\
\hline Model sepatu & $\bullet$ & Flatsoes \\
& $\bullet$ & Wedges \\
& $\bullet$ & Heels \\
\hline Jenis penyatuan & $\bullet$ & Jahit \\
komponen sepatu & $\bullet$ & Lem \\
& & \\
\hline Harga produk & $\bullet$ & Rp201.000,00- \\
& Rp300.000,00 \\
& $\bullet$ & Rp301.000,00- \\
& Rp400.000,00 \\
& $\bullet$ & Rp401.000,00- \\
& Rp500.000,00 \\
& $\bullet$ & Kulit \\
Material & $\bullet$ & Kulit Imitasi \\
kombinasi sepatu & $\bullet$ & Suede \\
& $\bullet$ & Denim \\
& $\bullet$ & Beludru \\
& $\bullet$ & \\
\hline
\end{tabular}

\subsection{Penyusunan dan Penyebaran Kuesioner}

Bentuk kuesioner dari choice based conjoint terdiri dari beberapa pertanyaan dengan masing-masing pertanyaan memiliki beberapa pilihan jawaban yang berupa stimuli-stimuli. Pertanyaan dalam choice based conjoint dapat bersifat random task, fixed task, maupun kombinasi keduanya. Choice based conjoint dapat menggunakan 20 choice task atau pertanyaan tanpa mengurangi kualitas data yang didapatkan karena pada jumlah pertanyaan tersebut, tidak ada bukti peningkatan random error. Satu pertanyaan choice based conjoint terdiri dari 2 sampai dengan 5 choice atau pilihan jawaban, tidak termasuk pilihan "tidak memilih sama sekali" (Johnson \& Orme, 1996). Pilihan "tidak memilih sama sekali" boleh digunakan, tetapi boleh juga tidak digunakan. Analisis konjoin memerlukan 4 sampai dengan 8 pertanyaan holdout (Hair, Black, Babin, \& Anderson, 2010).

Terdapat rule of thumb untuk menentukan jumlah sampel minimal untuk choice based conjoint yang dinyatakan dalam rumus sebagai berikut (Johnson \& Orme, 1996).

$$
\frac{n t a}{c} \geq 500
$$

Dimana:

$\mathrm{n}=$ jumlah sampel minimum yang dibutuhkan

$\mathrm{t}=$ jumlah task

$\mathrm{a}=$ jumlah alternatif per task tanpa pilihan none

$\mathrm{c}=$ jumlah level terbanyak

Dalam penelitian ini, peneliti membagikan enam variasi kuesioner kepada responden. Peneliti membuat enam variasi kuesioner karena salah satu syarat dari choice based conjoint adalah stimuli yang diberikan kepada responden harus bersifat random task bukan fixed task. Keenam variasi kuesioner tersebut diberi kode kuesioner A hingga kuesioner F. Responden secara random mengambil salah satu dari enam variasi kuesioner tersebut.

Setiap kuesioner terdiri atas dua bagian. Bagian pertama merupakan pertanyaan seputar profil demografis responden seperti usia, pekerjaan, penghasilan, dan pengeluaran. Bagian kedua dari kuesioner berisi choice task dari analisis konjoin. Dalam satu kuesioner terdapat 20 choice task utama dan 4 choice task holdout. Choice task utama berisi stimuli yang digunakan untuk mengestimasi nilai utilitas level dan bobot kepentingan atribut, sedangkan choice task holdout berisi stimuli yang digunakan untuk memvalidasi nilai utilitas level dan bobot kepentingan atribut yang telah diestimasi sebelumnya. Dalam satu choice task terdapat tiga kombinasi level masing-masing atribut serta satu pilihan "NONE". Pilihan "NONE" dapat dipilih oleh responden jika tidak ada satupun dari ketiga kombinasi dalam satu choice task yang disukai oleh responden tersebut. Tabel 2 mengilustrasikan format penilaian choice task pada kuesioner konjoin yang dirancang peneliti. 
Tabel 2. Contoh Pertanyaan Dalam Kuesioner

\begin{tabular}{|l||l|l|}
\hline \multirow{4}{*}{ Task 1 } & \multicolumn{2}{|c|}{ Profil 1 } \\
\cline { 2 - 3 } & Model Sepatu & Sandal \\
\cline { 2 - 3 } & Motif Etnik & Tenun \\
\cline { 2 - 3 } & Bahan Kombinasi & Kulit \\
\cline { 2 - 3 } & Jenis Pemasangan & Jahit \\
\hline Harga Sepatu & 401-500 ribu \\
\hline
\end{tabular}

\begin{tabular}{|l|l|}
\hline \multicolumn{2}{|c|}{ Profil 2} \\
\hline Model Sepatu & Flatshoes \\
\hline Motif Etnik & Batik \\
\hline Bahan Kombinasi & Kulit Imitasi \\
\hline Jenis Pemasangan & Jahit \\
\hline Harga Sepatu & $401-500$ ribu \\
\hline \multicolumn{2}{|c|}{$\checkmark$} \\
\hline
\end{tabular}

\begin{tabular}{|l|l|}
\hline \multicolumn{2}{|c|}{ Profil 3 } \\
\hline Model Sepatu & Flatshoes \\
\hline Motif Etnik & Songket \\
\hline Bahan Kombinasi & Beludru \\
\hline Jenis Pemasangan & Lem \\
\hline Harga Sepatu & $301-400$ ribu \\
\hline \multicolumn{2}{|c|}{} \\
\hline
\end{tabular}

digunakan berupa level-level setiap atribut dalam penelitian ini. Tetapi, tidak semua level digunakan sebagai variabel pengklaster karena hal tersebut dapat menimbulkan multikolinearitas. Untuk menghindari multikolinearitas tersebut, peneliti melakukan analisis korelasi terlebih dahulu. Untuk variabel-variabel yang memiliki korelasi, peneliti akan mengambil salah satu variabel saja. Analisis korelasi yang dilakukan menggunakan Uji Kendall's Tau. Dari hasil analisis korelasi tersebut, peneliti mengambil level "sandal", "flatshoes", "songket", "kulit imitasi", "kulit", "suede", "jahit", "201-300 ribu", dan "301-400 ribu" sebagai variabel pengklaster pada analisis klaster. Hal tersebut dilakukan karena kesembilan level tersebut sudah berkorelasi dengan variabelvariabel lainnya sehingga dengan mengambil kesembilan level tersebut, sudah turut menjelaskan level-level lainnya.

Dari hasil pengolahan data dengan analisis klaster, dipilih jumlah klaster sebanyak tiga klaster. Jumlah klaster tersebut dipilih karena memiliki rasio selisih antar bilangan aglomerasi yang paling kecil atau dengan kata lain memiliki jarak dua titik yang paling curam serta memiliki bilangan aglomerasi yang terbesar kedua. Dari hasil pengklasteran, didapat jumlah anggota klaster 1 sebanyak 85 responden atau dapat diprediksi market share klaster ini sebesar 56,67\%. Jumlah anggota klaster 2 sebanyak 21 responden atau dapat diprediksi klaster memiliki market share sebesar $14,00 \%$. Jumlah anggota klaster 3 sebanyak 44 responden atau dapat diprediksi market share klaster ini sebesar 29,33\%. Setelah melakukan uji konsistensi dengan melihat similaritas hasil antara metode hierarchical cluster dengan metode $K$-means cluster, didapatkan hasil uji konsistensi sebesar 74,67\%. Hal tersebut berarti klaster yang terbentuk sudah valid karena lebih besar dari nilai minimum ketepatan penempatan sebesar 20\% (Hair, Black, Babin, \& Anderson, 2010) mengelompokkan data. Variabel pengklaster yang 
Klaster-klaster yang terbentuk dari analisis klaster perlu dijelaskan bagaimana karakteristiknya. Karakteristik masing-masing klaster tersebut dapat dijelaskan menggunakan variabel demografis yang memiliki korelasi dengan klaster yang terbentuk. Peneliti menggunakan uji Chi Square untuk mengetahui variabel-variabel yang berkorelasi dengan klaster yang terbentuk karena data demografis yang digunakan merupakan data dengan skala nominal. Dari hasil perbandingan dengan tabel distribusi $c h i$ square, didapatkan hasil bahwa ada lima variabel yang terbukti berpengaruh terhadap klaster yang telah terbentuk, yaitu usia, pendidikan, pekerjaan, penghasilan per bulan, dan pengeluaran per bulan

\subsection{Analisis Konjoin Agregate}

Setelah didapatkan hasil analisis klaster berupa jumlah klaster yang terbentuk beserta anggota-anggotanya, perlu didefinisikan bagaimana preferensi masing-masing klaster mengenai atribut-atribut produk sepatu Klastik Footwear. Untuk mengetahui bagaimana preferensi konsumen potensial mengenai atribut sepatu Klastik Footwear, digunakan perhitungan analisis konjoin secara agregat di tiap klaster yang melibatkan anggota masing-masing klaster. Bobot kepentingan atribut tiap klaster dapat dilihat pada Tabel

Tabel 3. Bobot kepentingan Atribut Agregat Per Klaster

\begin{tabular}{llllll}
\hline \multicolumn{2}{c}{ Klaster 1 } & \multicolumn{2}{c}{ Klaster 2 } & \multicolumn{2}{c}{ Klaster 3 } \\
\hline Model & 28,31 & Model & 28,47 & Model & 4,81 \\
\hline Motif & 4,94 & Motif & 13,73 & Motif & 10,03 \\
\hline Bahan & 22,19 & Bahan & 40,79 & Bahan & 48,45 \\
\hline Assembly & 16,85 & Assembly & 1,30 & Assembly & 22,83 \\
\hline Harga & 27,71 & Harga & 15,71 & Harga & 13,88 \\
\hline
\end{tabular}

Nilai utilitas level dan atribut bobot yang dihasilkan dari analisis konjoin perlu diuji validitasnya. Uji validitas pada analisis konjoin dapat dilakukan dengan menghitung nilai hit ratio. Nilai hit ratio dapat dihitung dengan membandingkan jawaban aktual dari responden dengan jawaban hasil prediksi dari nilai utilitas level dan bobot atribut yang diperoleh dari analisis konjoin. Kriteria hit ratio yang baik adalah jika sama atau melebihi kesempatan klasifikasi ditambah seperempat dari kesempatan klasifikasi tersebut (Bajpai, 2011).

Dari hasil perhitungan hit ratio yang dilakukan, keempat pertanyaan holdout pada seluruh klaster memiliki nilai hit ratio lebih tinggi dari kriteria nilai hit ratio yang baik sehingga dapat disimpulkan bahwa nilai utilitas level dan bobot atribut yang dihasilkan analisis konjoin pada klaster ini dapat memprediksi dengan baik jawaban responden.
Tabel 4 merupakan rekapitulasi hasil analisis klaster dan analisis konjoin masingmasing klaster. Rekapitulasi tersebut merupakan karakteristik masing-masing klaster. Dari karakteristik demografis klaster 1, anggota dari klaster ini sebagian besar merupakan mahasiswa yang sedang menempuh program pasca sarjana. Anggota klaster ini kemungkinan besar merupakan konsumen yang mementingkan keamanan dan kenyamanan sebuah sepatu serta orang-orang yang relatif sensitif terhadap harga karena anggota klaster ini mementingkan model sepatu, harga sepatu, dan material kombinasi sepatu. Hal tersebut sesuai dengan karakteristik demografis klaster ini. Mahasiswa pasca sarjana adalah mahasiswa yang relatif aktif dan memiliki beberapa kegiatan sehingga mereka memperhatikan atribut keamanan dan kenyamanan dalam membeli sepatu. Namun, karena mayoritas dari anggota klaster ini masih berprofesi sebagai mahasiswa, mereka juga mempertimbangkan atribut harga dalam membeli sepatu dan relatif sensitif terhadap harga. 
Tabel 4. Rekapitulasi Hasil Analisis Klaster dan Analisis Konjoin

\begin{tabular}{|c|c|c|c|c|c|c|c|}
\hline \multirow{2}{*}{$\begin{array}{c}\text { Klast } \\
\text { er }\end{array}$} & \multicolumn{5}{|c|}{ Demografis } & \multirow{2}{*}{$\begin{array}{l}\text { Atribut yang } \\
\text { Dipentingkan }\end{array}$} & \multirow{2}{*}{ Preferensi } \\
\hline & $\begin{array}{c}\text { Usi } \\
\text { a }\end{array}$ & $\begin{array}{c}\text { Pendidik } \\
\text { an }\end{array}$ & $\begin{array}{c}\text { Pekerja } \\
\text { an }\end{array}$ & Penghasilan & Pengeluaran & & \\
\hline 1 & $\begin{array}{l}25- \\
29 \\
\text { tahu } \\
\mathrm{n}\end{array}$ & S1 & $\begin{array}{l}\text { Pelajar/ } \\
\text { Mahasis } \\
\text { wa }\end{array}$ & $\begin{array}{l}\text { Rp1.000.001,0 } \\
0- \\
\text { Rp5.000.000,0 } \\
0\end{array}$ & $\begin{array}{l}\text { Rp1.000.001,0 } \\
0- \\
\text { Rp5.000.000,0 } \\
0\end{array}$ & $\begin{array}{lr}\bullet & \text { Model } \\
\text { Sepatu } & \\
\bullet & \text { Harga } \\
\text { Sepatu } & \\
\bullet & \text { Material } \\
\text { Kombinasi Sepatu }\end{array}$ & $\begin{array}{l}\text { Sepatu flatshoes yang } \\
\text { terbuat dari kulit dan } \\
\text { bermotif tenun, jenis } \\
\text { penyatuan } \\
\text { komponennya } \\
\text { menggunakan dijahit } \\
\text { serta memiliki harga } \\
\text { dalam rentang Rp } \\
201.000,00-\mathrm{Rp} \\
300.000,00 \text {. }\end{array}$ \\
\hline 2 & $\begin{array}{l}18- \\
24 \\
\text { tahu } \\
\mathrm{n}\end{array}$ & SMA & $\begin{array}{l}\text { Pelajar/ } \\
\text { Mahasis } \\
\text { wa }\end{array}$ & $\begin{array}{l}<\mathrm{Rp} 1.000 .000 \\
, 00\end{array}$ & $\begin{array}{l}<\mathrm{Rp} 1.000 .000 \\
, 00\end{array}$ & $\begin{array}{lc}\bullet & \text { Material } \\
\text { Kombinasi Sepatu } \\
\bullet & \text { Model } \\
\text { Sepatu } & \\
\bullet & \text { Harga } \\
\text { Sepatu } & \end{array}$ & $\begin{array}{l}\text { Sepatu sandal yang } \\
\text { terbuat dari suede dan } \\
\text { bermotif tenun, jenis } \\
\text { penyatuan } \\
\text { komponennya } \\
\text { menggunakan dijahit } \\
\text { serta memiliki harga } \\
\text { dalam rentang Rp } \\
201.000,00-\mathrm{Rp} \\
300.000,00\end{array}$ \\
\hline 3 & $\begin{array}{l}25- \\
29 \\
\text { tahu } \\
n\end{array}$ & S1 & $\begin{array}{l}\text { Pelajar/ } \\
\text { Mahasis } \\
\text { wa }\end{array}$ & $\begin{array}{l}\text { Rp1.000.001,0 } \\
0 \text { - Rp } \\
5.000 .000,00\end{array}$ & $\begin{array}{l}\text { Rp1.000.001,0 } \\
0- \\
\text { Rp5.000.000,0 } \\
0\end{array}$ & $\begin{array}{lc}\bullet & \text { Material } \\
\text { Kombinasi Sepatu } \\
\bullet & \text { Jenis } \\
\text { Penyatuan Sepatu } \\
\bullet \quad \text { Harga } \\
\text { Sepatu } & \end{array}$ & $\begin{array}{l}\text { Sepatu wedges yang } \\
\text { terbuat dari kulit } \\
\text { imitasi dan bermotif } \\
\text { batik, jenis penyatuan } \\
\text { komponennya } \\
\text { menggunakan dijahit } \\
\text { serta memiliki harga } \\
\text { dalam rentang Rp } \\
201.000,00-\mathrm{Rp} \\
300.000,00\end{array}$ \\
\hline
\end{tabular}

Untuk karakteristik demografis klaster 2, Anggota klaster sebagian besar merupakan mahasiswa yang sedang menempuh program diploma maupun sarjana. Mahasiswa diploma dan sarjana adalah mahasiswa yang aktif dan memiliki banyak kegiatan sehingga mereka sangat memperhatikan atribut keamanan dan kenyamanan dalam membeli sepatu. Anggota klaster ini sensitif terhadap harga karena mayoritas dari anggota klaster ini masih berprofesi sebagai mahasiswa diploma dan sarjana dan penghasilan mereka kurang dari Rp 1.000.000,00 per bulan. Hal tersebut terlihat dari hasil analisis konjoin, yaitu atribut yang dipentingkan anggota klaster ini salah satunya adalah harga sepatu.
Sedangkan Anggota klaster 3 merupakan mahasiswa program pasca sarjana. Anggota klaster ini kemungkinan besar merupakan konsumen yang mementingkan aspek kenyamanan dalam menggunakan sepatu, ketahanan sepatu dan sensitif terhadap harga produk karena anggota klaster ini mementingkan material kombinasi sepatu, jenis penyatuan komponen sepatu, dan harga sepatu. Hal tersebut sesuai dengan karakteristik demografis klaster ini, yaitu mahasiswa pasca sarjana yang aktif dan memiliki beberapa kegiatan di luar ruangan, sehingga mereka memperhatikan atribut kenyaman dalam membeli sepatu. Mereka juga ingin memiliki sepatu yang relatif awet dan tahan terhadap berbagai situasi. Kedua alasan tersebut membuat anggota klaster ini mempertimbangkan atribut 
kenyamanan dan ketahanan sepatu. Anggota klaster ini juga mempertimbangkan atribut harga dalam membeli sepatu dan relatif sensitif terhadap harga karena sebagian dari anggota klaster ini masih berprofesi sebagai mahasiswa.

Seperti yang telah dijelaskan pada pendahuluan, Klastik Footwear ingin mengevaluasi produk-produknya yang sudah ada saat ini. Klastik footwear ingin mengurangi ragam produknya dan hanya mempertahankan produk- produk yang diprediksi akan sering dipesan oleh konsumen. Untuk menentukan produk mana yang diprediksi akan sering dipesan oleh konsumen, peneliti melakukan market simulation dari hasil analisis konjoin pada masing-masing klaster. Market share masing-masing produk yang dihasilkan pada market simulator ini menggambarkan prediksi produk-produk mana yang akan sering maupun jarang dipesan oleh konsumen.

Tabel 5. Market Share Produk Klastik Footwear

\begin{tabular}{|c|c|c|c|c|c|c|c|c|}
\hline \multicolumn{3}{|c|}{ Klaster 1} & \multicolumn{3}{|c|}{ Klaster 2} & \multicolumn{3}{|c|}{ Klaster 3} \\
\hline Produk & $\begin{array}{c}\text { Jumla } \\
\text { h } \\
\text { Respo } \\
\text { nden }\end{array}$ & $\begin{array}{c}\text { Market } \\
\text { Share } \\
(\%)\end{array}$ & $\begin{array}{c}\text { Produ } \\
\mathbf{k}\end{array}$ & $\begin{array}{c}\text { Jumlah } \\
\text { Respon } \\
\text { den }\end{array}$ & $\begin{array}{c}\text { Market } \\
\text { Share } \\
(\%)\end{array}$ & Produk & $\begin{array}{c}\text { Jumlah } \\
\text { Respon } \\
\text { den }\end{array}$ & $\begin{array}{c}\text { Market } \\
\text { Share } \\
(\%)\end{array}$ \\
\hline Ara & 8 & $9,41 \%$ & $\begin{array}{l}\text { Gendhi } \\
\text { s } 2\end{array}$ & 2 & $9,52 \%$ & $\begin{array}{l}\text { Gendhis } \\
2\end{array}$ & 4 & $9,09 \%$ \\
\hline $\begin{array}{l}\text { Gendhis } \\
2\end{array}$ & 7 & $8,24 \%$ & Danyar & 1 & $4,76 \%$ & Serena & 4 & $9,09 \%$ \\
\hline Srikandi & 7 & $8,24 \%$ & Gelatik & 1 & $4,76 \%$ & $\begin{array}{l}\text { Srikand } \\
\text { i }\end{array}$ & 4 & $9,09 \%$ \\
\hline Ratna & 6 & $7,06 \%$ & $\begin{array}{l}\text { Gendhi } \\
\text { s }\end{array}$ & 1 & $4,76 \%$ & Arimbi & 3 & $6,82 \%$ \\
\hline Arimbi & 5 & $5,88 \%$ & Kiara 2 & 1 & $4,76 \%$ & Ara & 2 & $4,55 \%$ \\
\hline Gendhis & 5 & $5,88 \%$ & $\begin{array}{l}\text { Senggi } \\
\text { gi }\end{array}$ & 1 & $4,76 \%$ & Danyar & 2 & $4,55 \%$ \\
\hline Geulis & 4 & $4,71 \%$ & Serena & 1 & $4,76 \%$ & Gelatik & 2 & $4,55 \%$ \\
\hline Kiara & 4 & $4,71 \%$ & Sitha & 1 & $4,76 \%$ & $\begin{array}{l}\text { Larantu } \\
\mathrm{ka}\end{array}$ & 2 & $4,55 \%$ \\
\hline Serena & 4 & $4,71 \%$ & Soko & 1 & $4,76 \%$ & Kiara & 1 & $2,27 \%$ \\
\hline Soko & 4 & $4,71 \%$ & $\begin{array}{l}\text { Srikand } \\
\mathrm{i}\end{array}$ & 1 & $4,76 \%$ & Ratna & 1 & $2,27 \%$ \\
\hline Brastagi & 3 & $3,53 \%$ & $\begin{array}{l}\text { Brastag } \\
\text { i }\end{array}$ & 6 & $28,57 \%$ & Widuri & 1 & $2,27 \%$ \\
\hline
\end{tabular}




\begin{tabular}{|c|c|c|c|c|c|c|c|c|}
\hline \multicolumn{3}{|c|}{ Klaster 1} & \multicolumn{3}{|c|}{ Klaster 2} & \multicolumn{3}{|c|}{ Klaster 3} \\
\hline Produk & $\begin{array}{c}\text { Jumla } \\
\text { h } \\
\text { Respo } \\
\text { nden }\end{array}$ & $\begin{array}{c}\text { Market } \\
\text { Share } \\
(\%)\end{array}$ & $\begin{array}{c}\text { Produ } \\
\mathbf{k}\end{array}$ & $\begin{array}{c}\text { Jumlah } \\
\text { Respon } \\
\text { den }\end{array}$ & $\begin{array}{c}\text { Market } \\
\text { Share } \\
(\%)\end{array}$ & Produk & $\begin{array}{c}\text { Jumlah } \\
\text { Respon } \\
\text { den }\end{array}$ & $\begin{array}{c}\text { Market } \\
\text { Share } \\
(\%)\end{array}$ \\
\hline $\begin{array}{l}\text { Larantuk } \\
\text { a }\end{array}$ & 3 & $3,53 \%$ & Telaga & 4 & $19,05 \%$ & Soko & 7 & $15,91 \%$ \\
\hline $\begin{array}{l}\text { Srikandi } \\
2\end{array}$ & 3 & $3,53 \%$ & Ara & 0 & $0.00 \%$ & Galuh & 6 & $13,64 \%$ \\
\hline Kiara 2 & 2 & $2,35 \%$ & Arimbi & 0 & $0.00 \%$ & Rinjani & 5 & $11,36 \%$ \\
\hline Senggigi & 2 & $2,35 \%$ & Gelatik & 0 & $0.00 \%$ & Brastagi & 0 & $0.00 \%$ \\
\hline Telaga & 2 & $2,35 \%$ & Geulis & 0 & $0.00 \%$ & Gendhis & 0 & $0.00 \%$ \\
\hline Galuh & 14 & $16,47 \%$ & Kiara & 0 & $0.00 \%$ & Geulis & 0 & $0.00 \%$ \\
\hline Danyar & 1 & $1,18 \%$ & $\begin{array}{l}\text { Larantu } \\
\mathrm{ka}\end{array}$ & 0 & $0.00 \%$ & Kiara 2 & 0 & $0.00 \%$ \\
\hline Widuri & 1 & $1,18 \%$ & Ratna & 0 & $0.00 \%$ & Sitha & 0 & $0.00 \%$ \\
\hline Gelatik & 0 & $0.00 \%$ & $\begin{array}{l}\text { Srikand } \\
\text { i } 2\end{array}$ & 0 & $0.00 \%$ & $\begin{array}{l}\text { Srikand } \\
\text { i } 2\end{array}$ & 0 & $0.00 \%$ \\
\hline Sitha & 0 & $0.00 \%$ & Widuri & 0 & $0.00 \%$ & Telaga & 0 & $0.00 \%$ \\
\hline Total & 85 & $100,00 \%$ & Total & 21 & $100,00 \%$ & Total & 44 & $100,00 \%$ \\
\hline
\end{tabular}

Seperti yang dapat dilihat pada Tabel 5, pada klaster 1, produk Galuh memiliki market share terbesar mencapai 16,47\%. Disusul dengan produk Ara sebesar 9,41\%\%. Kemudian disusul oleh produk Gendhis 2 dan Srikandi dengan masing-masing market share sebesar 8,24\%. Dari Tabel 5 dapat dilihat bahwa pada klaster 2, produk yang memiliki market share terbesar adalah produk Brastagi, yaitu $28,57 \%$. Produk yang memiliki market share terbesar berikutnya adalah produk Telaga sebesar 19,05\% dan produk Gendhis 2 sebesar 9,52\%. Pada Tabel 5 dapat dilihat bahwa pada klaster 3, produk Klastik Footware yang memiliki market share terbesar adalah produk Soko, yaitu 15,91\%. Produk berikutnya yang memiliki market share terbesar kedua dan ketiga adalah Produk Galuh sebesar $13,64 \%$, dan produk Rinjani sebesar 11,36\%.
Dari hasil market simulator tersebut, Klastik Footwear dapat mempertahankan produk Galuh, Ara, Srikandi, Gendhis 2, Brastagi, Telaga, Rinjani dan Soko dibandingkan produk yang lain. Hal tersebut dikarenakan produk-produk tersebut merupakan produk yang diprediksi sering dipesan oleh konsumen dibanding produk Klastik Footwear lainnya.

\section{Simpulan}

Dari hasil analisis klaster dan Analisis klaster konjoin menghasilkan 3 klaster konsumen potensial Klastik Footwear. Klaster 1 berjumlah $56,67 \%$ dari jumlah responden dan merupakan klaster konsumen yang mementingkan keamanan dan kenyamanan sebuah sepatu serta orang-orang yang relatif sensitif terhadap harga. Kemudian klaster 2 berjumlah $14 \%$ dari jumlah responden 
dan merupakan klaster yang mementingkan atribut material kombinasi sepatu, model sepatu dan harga sepatu. Klaster ini terdiri konsumen yang sensitif terhadap harga produk yang dibelinya dan mementingkan keamanan serta kenyamanan sebuah sepatu karena ketiga atribut tersebut yang paling dipentingkan oleh anggota klaster ini. Sedangkan klaster 3 berjumlah 29,33\% dari total responden dan merupakan klaster yang mementingkan atribut material kombinasi sepatu, jenis penyatuan komponen sepatu. Anggota klaster ini merupakan konsumen yang mementingkan aspek kenyamanan dalam menggunakan sepatu, ketahanan sepatu dan sensitif terhadap harga produk.

Saat ini, Klastik Footwear ingin mengurangi ragam produknya dan hanya mempertahankan produk-produk yang diprediksi akan sering dipesan oleh konsumen potensial. Produk-produk yang diprediksi sering dipesan oleh konsumen klaster 1 adalah produk Galuh, Ara, Srikandi dan Gendhis 2. Sedangkan konsumen di klaster 2 diprediksi memilih memesan produk Brastagi, Telaga dan Gendhis 2 dan produk yang diprediksi sering dipesan oleh konsumen klaster 3 adalah produk Rinjani, Galuh, dan Soko.

\section{Ucapan Terima Kasih}

Peneliti mengucapkan terima kasih kepada semua pihak khususnya kepada Lembaga Penelitian dan Pengabdian Masyarakat Institut Teknologi Telkom Surabaya atas dukungan materi serta moril, terutama bantuan dana melalui Program Penelitian Dana Internal. Penyelenggara juga mengucapkan terima kasih kepada Civitas Akademika Prodi Teknik Industri dan Fakultas Teknologi Informasi dan Industri atas dukungan moril.

\section{Daftar Referensi}

Badan Pusat Statistik. (2014, Mei 2015 26). Jumlah Perusahaan Industri Mikro Kecil menurut 2-digit KBLI, 2010-2014. Retrieved from www.bps.go.id

Bajpai, N. (2011). Business Research Methods. New York: Pearson Education.
Bleibaum, R. N., Kern, M. J., \& Thomas, H. (2017). Contextual product testing for small to medium sized enterprises (SMEs). The Effects of Environment on Product Design and Evaluation, 501520.

Dauda, S. Y., \& Lee, J. (2016). Quality of service and customer satisfaction: a conjoint analysis for the Nigerian bank customers. International Journal of Bank Marketing, 34(6), 841-867.

Hair, J. F., Black, W. C., Babin, B. J., \& Anderson, R. E. (2010). Multivariate Data Analysis. New Jersey: Pearson Prentice Hall.

Johnson, R. M., \& Orme, B. K. (1996). How Many Questions Should You Ask in ChoiceBased Conjoint Study. Sawtooth Software Research Paper Series.

Kosasih, W., Salomon, L. L., \& Hutomo, R. (2017). Using Conjoint and Cluster Analysis in Developing New Product for Micro, Small, and Medium Enterprises (SMEs) based on Customer Preferences (Case Study: Lampung Province's Banana Chips). International Conference on Mathematics : Pure, Applied, and Computation. AIP Publishing.

Kuzmanovic, M., Martic, M., \& Gusavac, B. A. (2011). using Conjoint Analysis to Assess Customer Management in The Product Development Process. 1st International Symposium Engineering Management and Competitiveness (pp. 353-358). Republic of Serbia: Technical Faculty, University of Novi Sad.

Machmud, S., \& Sidharta, I. (2016). Entrepreneurial Motivation and Business Performance of SMEs in the SUCI Clothing Center, bandung, Indonesia. DLSU Business \& Economic, 63-78.

Maholtra, N. K., \& Birks, D. F. (2007). Marketing Research : An Applied Orientation 3rd Edition. Milan: Prentice Hall.

Muliatie, Y. E., \& Riyadi, A. (2019). Membangun Brand Image pada UKM Alas Kaki 
Sidoarjo. Jurnal Mitra Manajemen, 3(4), 397-409.

Sidharta, I., \& Lusyana, D. (2014). CompetencyBased Analysis Concept Determinants of Knowledge, Skill, and Ability (KSA) In Center of Clothing Suci, Bandung. Jurnal Computech \& Bisnis, 8(1), 49-60.

Simamora, B. (2005). Analisis Multivariat Pemasaran. Jakarta: Gramedia Pustaka Utama.

Suci, Y. R. (2017). Perkembangan UMKM (Usaha Mikro, Kecil, dan Menengah) di Indonesia. Jurnal Ilmiah fakultas Ekonomi, 6(1), 51-58.

Sudaryo, Y., \& Purnamasari, D. (2017). Strategy Development Micro Small and Medium Business Performance in Small and Medium Enterprises Cibaduyut Shoe Bandung. Journal of Scientific \& Technology Research, 6(3), 102-105.

Sugih, I. L., \& Soekarno, S. (2014). Lesson Learned from Indonesian Biggest Fashion Retailer Company to Encourage the Development of Small Fashion Business. Social and Behavioral Science, 169, 240-248. 